\title{
Incidence and Predictors of Tuberculosis among HIV Positive Children at University of Gondar Referral Hospital, Northwest Ethiopia: A Retrospective Follow-Up Study
}

\author{
Sualiha Gebeyaw Ayalaw, ${ }^{1}$ Kefyalew Addis Alene, ${ }^{2}$ and Akilew Awoke Adane ${ }^{2}$ \\ ${ }^{1}$ Addis Ababa Health Bureau, Addis Ababa, Ethiopia \\ ${ }^{2}$ Department of Epidemiology and Biostatistics, Institute of Public Health, College of Medicine and Health Sciences, \\ University of Gondar, P.O. Box 196, Gondar, Ethiopia
}

Correspondence should be addressed to Akilew Awoke Adane; akilew24@gmail.com

Received 4 September 2014; Revised 9 April 2015; Accepted 21 April 2015

Academic Editor: José A. Oteo

Copyright (c) 2015 Sualiha Gebeyaw Ayalaw et al. This is an open access article distributed under the Creative Commons Attribution License, which permits unrestricted use, distribution, and reproduction in any medium, provided the original work is properly cited.

\begin{abstract}
Background. The aim of this study was to determine the incidence of tuberculosis and its predictors among HIV positive children. Methods. A six-year retrospective follow-up study was conducted among HIV infected children aged less than 15 years. Life table was used to estimate the cumulative probability of tuberculosis free survival. Cox proportional hazards model was used to identify predictors of tuberculosis. Results. A total of $271 \mathrm{HIV}$ positive children were followed for six years and produced 1100.50 personyears of observation. During the follow-up period 52 new TB cases occurred. The overall incidence density of TB was 4.9 per 100 PY. Inappropriate vaccination [AHR: 8.03 (95\% CI; 4.61-13.97)], ambulatory functional status [AHR: 1.99 (95\% CI; 1.04-3.81)], and having baseline anemia [AHR: 2.23 (95\% CI; 1.19-4.15)] were important predictors of time to TB occurrence. Conclusion. TB incidence rate was high. Early diagnosis and treatment of anemia and strengthening immunization program would reduce the risk of TB occurrence.
\end{abstract}

\section{Background}

Tuberculosis (TB) is a leading cause of morbidity and mortality among HIV infected children. Worldwide, there are approximately nine million new TB cases each year and 13\% coinfected with HIV $[1,2]$. In 2011, there were estimated 9.2 million new cases of TB, with ten percent of those occurring in children, almost one million new pediatric cases each year [3-5]. TB is among the top ten causes of death among children [6]. One of three HIV coinfected patients dies because of TB and the disease will become worse if it was left untreated [7]. TB accounts for $26 \%$ of AIDS-related deaths, of which 99\% occur in developing countries [8]. In resource limited countries, TB is the most common opportunistic infection in children with HIV [9-12].

Several studies in Africa have shown that the incidence of TB among HIV positive children ranges from 1 to 9.9 per 100 PY [13-17].
In previous studies, severe wasting, severe immune suppression, anemia, and WHO stage IV were all independently associated with a higher risk of TB. In addition, the use of antiretroviral drugs for more than 180 days reduced the risk of TB [13]. Early initiation of ART (particularly before 12 weeks of age) in HIV infected infants regardless of clinical or $\mathrm{CD} 4$ count criteria significantly reduces mortality and $\mathrm{TB}$ incidence. Isoniazid preventive therapy (IPT) for TB-exposed infants is an important additional TB prevention strategy [18].

In Ethiopia, childhood TB is still a major cause of hospital admission and death [13]. In 2011, the number of new HIV infections among children was $13000,19 \%$ of eligible children younger than 15 years old receiving antiretroviral therapy [2]. But studies on various aspects of childhood tuberculosis are rare. Hence, studying the incidence of tuberculosis and its predictors among HIV positive children will have a great importance for the health care system in making appropriate adjustments and allocating resources as a solution. 


\section{Methods}

2.1. Study Design and Setting. A retrospective follow-up study was conducted in August 2013 at the University of Gondar Referral Hospital pediatrics HIV care clinic, which is located in Northwest Ethiopia. The hospital is the only tertiary hospital located in the historical city of Gondar, serving for more than five million people. During the study period, there were a total of 907 children ever enrolled into pediatrics chronic HIV care and follow-up clinic, 597 ever started ART, and the rest were pre-ART.

2.2. Definition of Tuberculosis. In the study setting, TB is diagnosed using chest radiology, fine needle aspiration, and cytology with very high clinical suspicion. When a child is diagnosed with active TB, the treatment is given according to the national TB treatment guideline. The event of this study was new occurrence of TB, which is defined as occurrence of TB in HIV infected children during the follow-up period at any time after enrollment to pediatrics HIV care clinic. Children, who were lost, died, or transferred out or did not develop the events until the last visit were considered as censored. In this study, severe immunodeficiency was defined as CD4 count below the threshold according to the child's age; for infants CD4 $<1500 / \mathrm{mm}^{3}$ (<25\%), 12-35 months $<750 \mathrm{~mm}^{3}$ (<20\%), 36-59 months $<350 \mathrm{~mm}^{3} \quad(<15 \%)$, and five years and above $<200 / \mathrm{mm}^{3}(<15 \%)$. Those HIV positive children above the threshold were classified as not severe immunodeficiency.

2.3. Inclusion and Exclusion Criteria. All HIV positive children below 15 years of age and newly enrolled into pediatric chronic HIV care clinic at the University of Gondar Referral Hospital from September 2006 to August 2010 were included in this study (Figure 1). Those HIV positive children who started anti-TB treatment at the beginning of the followup and those with incomplete baseline information such as CD4 count and hemoglobin (Hgb) level were excluded from the study. Finally, two hundred seventy-one children who fulfilled the inclusion criteria were included in this study.

2.4. Data Collection. All available information on patient registration book was checked and an appropriate data extraction tool was prepared. Then, data were extracted from patients' registration book by two health professionals who had ART training and have been working in HIV care clinic.

2.5. Data Analysis. Data were entered and cleaned using EPI INFO version 3.5.3 and exported to SPSS version 20 for analysis. Nutritional status was assessed using Anthro plus software. Summary statistics and incidence density rate were calculated. Life table was used to estimate the cumulative probability of TB free survival and Kaplan-meier to estimate the median TB free survival time. Bivariate and multivariate Cox proportional hazards model was used to identify predictors of time to TB occurrence. Adjusted Hazard Ratio (AHR) with 95\% confidence intervals (CI) was computed and statistical significance was considered at $P$ value $\leq 0.05$.

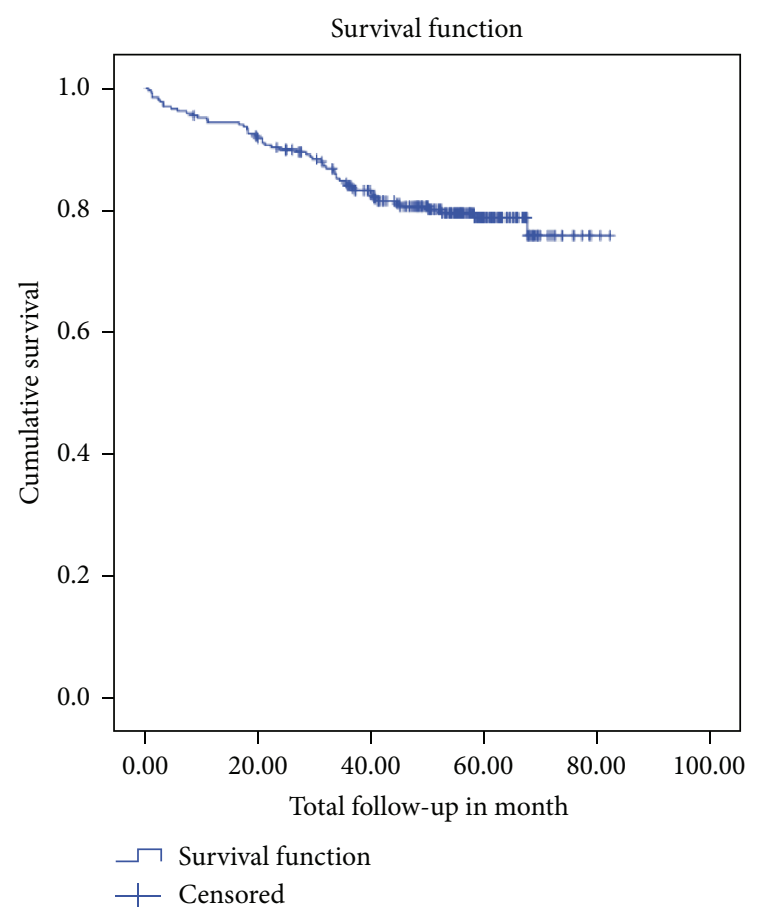

FIGURE 1: TB free survival proportion of HIV positive children at pediatrics HIV care clinic of University of Gondar Referral Hospital, from September 2006 to August 2013.

The necessary assumptions for Cox proportion hazard model were checked using the Schoen field residual test.

\section{Ethical Considerations}

Ethical clearance was obtained from the institutional review board of the University of Gondar. Formal letter of permission was obtained from the chief executive officer of the hospital. The Pediatrics ART head gave the consent for extracting data from records. Patients' names and identification numbers were not extracted to ensure confidentiality of patient information.

\section{Results}

4.1. Sociodemographic Characteristics of the Study Participants. Two hundred seventy-one HIV infected children were included in the analysis. The mean age was $6.42( \pm 3.53 \mathrm{SD})$ years and $41 \%$ of them were under 5 years. Slightly more than half $(51.7 \%)$ of them were females and about $85 \%$ of them were from urban areas. One in every eight (12.5\%) children was double orphan, who lost both of their partners, and one-third of them were living with more than 5 family sizes (Table 1).

4.2. Baseline Clinical Characteristics of Study Participants. Slightly more than half (53.9\%) of HIV positive children had a baseline CD 4 count of 350 and above. About $16 \%$ of them were anemic during enrolment. The baseline median CD4 
TABLE 1: Sociodemographic characteristics of HIV positive children at pediatrics HIV care clinic of the University of Gondar Referral Hospital, Northwest Ethiopia, from September 2006 to August 2010.

\begin{tabular}{|c|c|c|c|}
\hline Characteristics & Categories & Frequency & Percent \\
\hline \multirow{2}{*}{ Sex } & Male & 131 & 48.3 \\
\hline & Female & 140 & 51.7 \\
\hline \multirow{3}{*}{ Age } & $<5$ & 111 & 41.0 \\
\hline & $5-9$ & 102 & 37.6 \\
\hline & $10-14$ & 58 & 21.4 \\
\hline \multirow{2}{*}{ Residence } & Urban & 231 & 85.2 \\
\hline & Rural & 40 & 14.8 \\
\hline \multirow{5}{*}{ Parental status } & Both parents alive & 138 & 50.9 \\
\hline & Paternal orphan & 56 & 20.7 \\
\hline & Maternal orphan & 34 & 12.5 \\
\hline & Double orphan & 34 & 12.5 \\
\hline & Not recorded & 9 & 3.3 \\
\hline \multirow{3}{*}{ Family size } & $\leq 2$ & 29 & 10.7 \\
\hline & $3-4$ & 150 & 55.4 \\
\hline & $\geq 5$ & 92 & 33.9 \\
\hline \multirow{5}{*}{ Care givers } & Parents & 203 & 74.9 \\
\hline & Sibling & 24 & 8.9 \\
\hline & Grand parents & 26 & 9.6 \\
\hline & Guardians & 12 & 4.4 \\
\hline & Orphanage centers & 6 & 2.2 \\
\hline
\end{tabular}

and Hgb level were 388 (IQR; 193-716) and 12 (IQR; 11.313), respectively. During their follow-up, Co-Trimoxazole Preventive Therapy (CPT) was provided nearly for all (97.8\%) of patients and about $52 \%$ of them received Isoniazid (INH) prophylaxis. Nearly two-third (62\%) of them were stunted. During enrolment, about 55\%, 37.3\%, and 28.1\% HIV positive children had functional status of ambulatory, working, and being bedridden, respectively. Nearly one-fifth (16.6\%) had past history of TB treatment, and about $11 \%$ of them defaulted.

4.3. Tuberculosis Incidence Rate. Two hundred seventy-one study subjects were followed up for different periods ranging from one month to six years which resulted in 1100.49 personyears of observation. The mean follow-up time was 48.73 months $(S D \pm 17.87)$. Within the follow-up period, one-fifth (19.9\%) of new tuberculosis cases were observed and $11 \%$ were transferred out. The overall TB incidence density rate was 4.9 per 100 PY.

Nearly three-quarters $(70.3 \%)$ were pulmonary tuberculosis. Similar proportions $(70.3 \%)$ of Tb cases were on ART. The cumulative probability of TB free survival at the end of 6 months was 0.96; at the end of a year, 0.94; and that of survival at the end of three years was 0.84 and at the end of six years was 0.76 . The median survival time from enrolment to TB occurrence was 72 months.

4.4. Predictors of Time to TB Occurrence. In bivariate Coxregression analysis, paternal orphans, baseline WHO clinical stage IV, and having baseline anemia and being ambulatory and inappropriately vaccinated were significantly associated with incidence of TB among HIV positive children. However, in multivariate Cox-regression analysis, being inappropriately vaccinated and having baseline anemia and ambulatory functional status remained significant predictors of TB occurrence.

Those HIV infected children who had inappropriate vaccination were about 8 times (AHR 8.03 (95\% CI; 4.6113.97)) higher risk of developing $\mathrm{TB}$ at any time as compared to the counterpart. Those HIV infected children who had baseline anima are 2.2 (AHR 2.23 (95\% CI; 1.19-4.15)) times higher risk of developing $\mathrm{TB}$ at any time as compared to those HIV infected children who had no baseline anemia. HIV infected children who had ambulatory function status at enrollment were at 1.9 (AHR 1.99 (95\% CI; 1.04-3.81)) times higher risk of developing TB compared to those who were working (Table 2).

\section{Discussion}

This study revealed that the overall incidence density rate of TB among HIV positive children at University of Gondar Referral Hospital was 4.9 PY. It was similar with the finding from a cohort study in Tanzania (5.2 cases per $100 \mathrm{PY}$ ) [13]. But, this finding is higher than that of studies done in Kenya and South Africa which were 1.4 and 1.0 per 100 PY, respectively $[14,15]$. The discrepancies in incidence rate may be due to the difference in follow-up period of the studies and the difference in the overall burden of TB in the general population. But the rate was lower than the finding from a cohort study in Felege Hiwot Referral Hospital (Northern Ethiopia) which was 9.9 per 100 PY (7 cases out of 56 children followed up for 70.50 PY) [19]. This may be due to the difference in the study population (mixed adult and pediatric).

This study found that HIV positive children with baseline anemia had 2.23 times higher risk of developing $\mathrm{TB}$ as compared to nonanemic children which is similar to the studies done in Tanzania and Northern Ethiopia [13, 19]. This could be due to the fact that children were affected by infections when their Hgb level is lower than $12 \mathrm{~g} / \mathrm{dL}$. As a result, they become at higher risk for TB.

This study also found that patients with baseline ambulatory functional status had 2 times higher risk of developing $\mathrm{TB}$ as compared to working functional status. This finding is similar to the study done in Northern Ethiopia [20]. This could be due to the fact that patients lose their functional status as a result of many infectious diseases when they are anemic.

This study also revealed that patients who were not appropriately vaccinated had 8.03 times higher risk of developing TB as compared to vaccinated children. Similar finding in Tanzania showed that BCG scar was associated with a reduced risk of $\mathrm{TB}$, as research showed $\mathrm{BCG}$ vaccination considerably reduced the risk of TB, both among individuals with and without HIV infection [21].

Unlike the previous studies, the current study found that baseline clinical factors like immune suppression, WHO stage, ART status, and nutritional status were not associated 
TABLE 2: Cox-regression analysis of predictors of incidence of TB among HIV infected children at University of Gondar Referral Hospital $(n=271)$.

\begin{tabular}{|c|c|c|c|c|}
\hline \multirow{2}{*}{ Variables } & \multicolumn{2}{|c|}{ TB incidence } & \multirow{2}{*}{ CHR (95\% CI) } & \multirow{2}{*}{$\operatorname{AHR}(95 \% \mathrm{CI})$} \\
\hline & Event & Censored & & \\
\hline \multicolumn{5}{|l|}{ Sex } \\
\hline Male & 28 & 103 & 1 & \\
\hline Female & 26 & 114 & $0.84(0.49-1.43)$ & \\
\hline \multicolumn{5}{|l|}{ Age } \\
\hline$<5$ & 18 & 93 & $0.87(0.41-1.84)$ & \\
\hline $5-9$ & 25 & 77 & $1.33(0.65-2.69)$ & \\
\hline $10-14$ & 11 & 47 & 1 & \\
\hline \multicolumn{5}{|l|}{ Residence } \\
\hline Urban & 44 & 187 & 1 & \\
\hline Rural & 10 & 30 & $1.58(0.79-3.15)$ & \\
\hline \multicolumn{5}{|l|}{ Family size } \\
\hline$\leq 2$ & 6 & 23 & 1 & \\
\hline $3-4$ & 31 & 119 & $0.94(0.39-2.26)$ & \\
\hline$\geq 5$ & 17 & 75 & $0.82(0.32-2.07)$ & \\
\hline \multicolumn{5}{|l|}{ Parental status } \\
\hline Both parents a live & 22 & 116 & 1 & \\
\hline Paternal orphan & 17 & 39 & $2.05(1.09-3.87)$ & \\
\hline Maternal orphan & 7 & 27 & $1.26(0.54-2.95)$ & \\
\hline Double orphan & 5 & 29 & $0.90(0.34-2.38)$ & \\
\hline Not recorded & 3 & 6 & $2.27(0.68-7.58)$ & \\
\hline \multicolumn{5}{|l|}{ WHO clinical stage } \\
\hline I & 10 & 73 & 1 & \\
\hline II & 13 & 59 & $1.49(0.65-3.41)$ & \\
\hline III & 23 & 71 & $2.06(0.98-4.33)$ & \\
\hline IV & 8 & 14 & $3.66(1.44-9.29)$ & \\
\hline \multicolumn{5}{|l|}{ Anemia } \\
\hline Anemia & 15 & 27 & $2.47(1.36-4.49)$ & $2.23(1.19-4.15)$ \\
\hline No Anemia & 39 & 190 & 1 & \\
\hline \multicolumn{5}{|l|}{ Immunodeficiency } \\
\hline Severe & 20 & 77 & $1.08(0.62-1.87)$ & \\
\hline Not severe & 34 & 140 & 1 & \\
\hline \multicolumn{5}{|l|}{ ART at initial } \\
\hline Yes & 22 & 90 & $1.10(0.64-1.91)$ & \\
\hline No & 32 & 127 & 1 & \\
\hline \multicolumn{5}{|l|}{ IPT } \\
\hline Yes & 28 & 114 & $1.09(0.64-1.85)$ & \\
\hline No & 26 & 118 & 1 & \\
\hline \multicolumn{5}{|l|}{$\mathrm{CPT}$} \\
\hline Yes & 53 & 212 & $0.82(0.11-5.96)$ & \\
\hline No & 1 & 5 & 1 & \\
\hline \multicolumn{5}{|l|}{ Past TB treatment history } \\
\hline Yes & 11 & 34 & $0.82(0.11-5.96)$ & \\
\hline No & 43 & 183 & 1 & \\
\hline \multicolumn{5}{|l|}{ Functional status } \\
\hline Working & 13 & 88 & 1 & \\
\hline Ambulatory & 37 & 111 & $2.21(1.17-4.19)$ & $1.99(1.04-3.81)$ \\
\hline Bedridden & 4 & 18 & $1.50(0.49-4.61)$ & $0.92(0.29-2.92)$ \\
\hline \multicolumn{5}{|l|}{ Vaccination status } \\
\hline Vaccinated & 22 & 174 & 1 & \\
\hline Not appropriately vaccinated & 31 & 22 & $7.86(4.54-13.62)$ & $8.03(4.61-13.97)$ \\
\hline Not recorded & 1 & 21 & $0.36(0.05-2.64)$ & $0.42(0.06-3.15)$ \\
\hline \multicolumn{5}{|l|}{ Nutritional status } \\
\hline Normal & 19 & 84 & 1 & \\
\hline Stunted & 35 & 133 & $1.07(0.61-1.87)$ & \\
\hline
\end{tabular}

$\mathrm{COR}=$ Crude hazard ratio, $\mathrm{AOR}=$ Adjusted Hazard Ratio, and $\mathrm{CI}=$ confidence interval. 
with occurrence of TB. For instance, a study in Tanzania reported severe wasting ( $\mathrm{RR} 1.8,95 \%$ CI 1.3-2.5), severe immune suppression (RR 2.6, 95\% CI 1.8-3.8), and WHO stage IV (RR 4.5, 95\% CI 2.4-8.5) were all independently associated with a higher risk of TB [21]. In addition, the use of antiretroviral drugs for more than 180 days reduced the risk of $\mathrm{TB}$ by $70 \%$ ( $\mathrm{RR} 0.3,95 \% \mathrm{CI} 0.2-0.4$ ) [21]. The discrepancy might be due to methodology, study setting, and time variations.

The retrospective nature of the study was one of the limitations of this study. As a result, some of the important predictors which had a significant association with the TB occurrence in other studies like income were not included in this study.

\section{Conclusion}

Incidence of TB was high among HIV infected children, especially after the first six months of enrolment in HIV care. The baseline anemia, ambulatory functional status, and those who were not appropriately vaccinated were significantly associated with the incidence of tuberculosis. Therefore, early diagnosis and treatment of anemia and strengthening immunization program are recommended to reduce the risk of TB occurrence among HIV infected children.

\section{Conflict of Interests}

The authors declare that they have no conflict of interests.

\section{Authors' Contribution}

Sualiha Gebeyaw wrote the proposal, participated in data collection, analyzed the data, and drafted the paper. Kefyaelw Addis Alene and Akilew Awoke Adane approved the proposal with some revisions and participated in data collection, analysis, and paper writing. All authors read and approved the final paper.

\section{Acknowledgments}

The authors would like to extend their respect and acknowledgment to the administrations and staffs of University of Gondar Referral Hospital chronic HIV care clinic. The authors' gratitude also goes to the respondents and data collectors.

\section{References}

[1] WHO, Executive Summary Global Tuberculosis Report, 2012.

[2] P. H. Lagrange, S. K. Thangaraj, R. Dayal et al., "A toolbox for tuberculosis diagnosis: an indian multicentric study (20062008): microbiological results," PLoS ONE, vol. 7, no. 8, Article ID e43739, 2012.

[3] E. C. Pearce, J. F. Woodward, W. M. Nyandiko, C. Rachel Vreeman, and S. O. Ayaya, "A systematic review of clinical diagnostic systems used in the diagnosis of tuberculosis in children," AIDS Research and Treatment, vol. 2012, Article ID 401896, 11 pages, 2012.

[4] R. Lolekha, A. Anuwatnonthakate, S. Nateniyom et al., "Childhood TB epidemiology and treatment outcomes in Thailand: a TB active surveillance network, 2004 to 2006," BMC Infectious Diseases, vol. 8, article 94, 2008.

[5] N. G. Tena-Coki, T. J. Scriba, N. Peteni et al., "CD4 and CD8 T-cell responses to mycobacterial antigens in African children," American Journal of Respiratory and Critical Care Medicine, vol. 182, no. 1, pp. 120-129, 2010.

[6] S. Swaminathan and B. Rekha, "Pediatric tuberculosis: global overview and challenges," Clinical Infectious Diseases, vol. 50, supplement 3, pp. S184-S194, 2010.

[7] N. Rabirad, E. M. Nejad, R. Hadizadeh, J. Begjani, and S. R. Ehsani, "The prevalence of TB in HIV patients and risk factor with frequent referral (Iran, 2009-10)," Iranian Red Crescent Medical Journal, vol. 15, no. 1, pp. 58-61, 2012.

[8] A. Pawlowski, M. Jansson, M. Sköld, M. E. Rottenberg, and G. Källenius, "Tuberculosis and HIV co-infection," PLoS Pathogens, vol. 8, no. 2, Article ID e1002464, 2012.

[9] H. I. Nwokeukwu, P. N. Okafor, O. Okorie, and I. K. Ukpabi, "Paediatric multidrug-resistant tuberculosis with HIV coinfection: a case report," Case Reports in Medicine, vol. 2013, Article ID 756152, 3 pages, 2013.

[10] W. Manosuthi and J. Wongsawat, "Treatment challenges in Coinfected HIV and TB children," Indian Pediatrics, vol. 48, no. 12, pp. 937-938, 2011.

[11] H. A. Yumo, C. Kuaban, and F. Neuhann, "WHO recommended collaborative TB/HIV activities: evaluation of implementation and performance in a rural district hospital in Cameroon," The Pan African Medical Journal, vol. 10, p. 30, 2011.

[12] S. Bakeera-Kitaka, A. Conesa-Botella, A. Dhabangi et al., "Tuberculosis in human immunodeficiency virus infected Ugandan children starting on antiretroviral therapy," International Journal of Tuberculosis and Lung Disease, vol. 15, no. 8, pp. 1082-1086, 2011.

[13] N. Li, K. P. Manji, D. Spiegelman et al., "Incident tuberculosis and risk factors among HIV-infected children in Tanzania," AIDS, vol. 27, no. 8, pp. 1273-1281, 2013.

[14] Tuberculosis in HIV-Positive Children often Missed from Incidence Data: The Influence of HAART on Pediatric TB, 2006.

[15] L. L. Abuogi, C. Mwachari, H. H. Leslie et al., "Impact of expanded antiretroviral use on incidence and prevalence of tuberculosis in children with HIV in Kenya," International Journal of Tuberculosis and Lung Disease, vol. 17, no. 10, pp. 12911297, 2013.

[16] A. Edmonds, J. Lusiama, S. Napravnik, F. Kitetele, A. Van Rie, and F. Behets, "Anti-retroviral therapy reduces incident tuberculosis in HIV-infected children," International Journal of Epidemiology, vol. 38, no. 6, Article ID dyp208, pp. 1612-1621, 2009.

[17] E. Gizachew and D. Meaza, Incidence and Preddictors of TB among PLWHAS on HAART in Felege Hiwot Referal Hospital, Bahir Dar, Ethiopia, 2012.

[18] J. J. C. Nuttall and B. S. Eley, "BCG vaccination in HIV-infected children," Tuberculosis Research and Treatment, vol. 2011, Article ID 712736, 6 pages, 2011.

[19] E. Gizachew and D. Meaza, Incidence and Preddictors of TB among PLWHAS on HAART, Felege Hiwot Referal Hospital, Bahir Dar, Ethiopia, 2012. 
[20] A. Kefyalew, W. Belaynew, and N. Ansha, "Incidence and predictors of tuberculosis among adult people living with human immunodeficiency virus at the University of Gondar Referral Hospital, Northwest Ethiopia," BMC Infectious Diseases, vol. 13, article 292, 2013.

[21] D. Faurholt-Jepsen, N. Range, G. PrayGod et al., "BCG protects against tuberculosis irrespective of HIV status: a matched casecontrol study in Mwanza, Tanzania," Thorax, vol. 68, no. 3, pp. 288-289, 2013. 


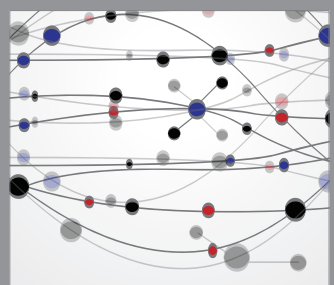

The Scientific World Journal
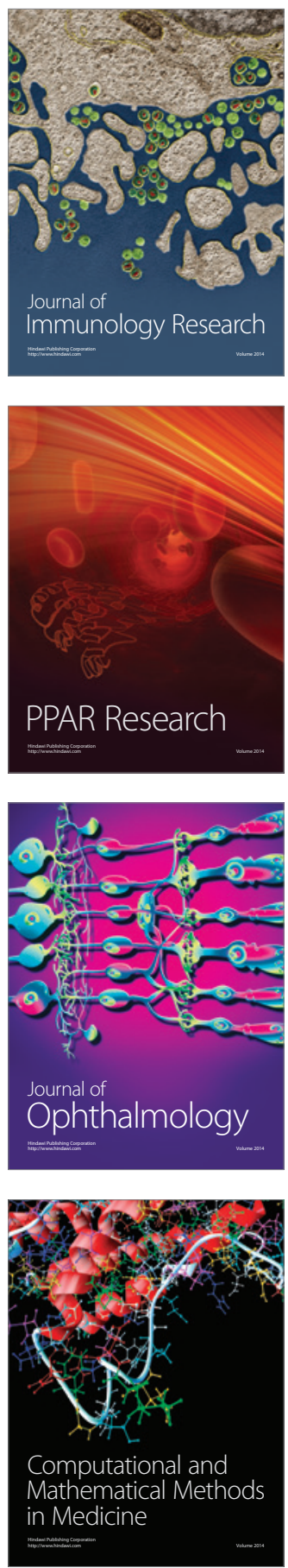

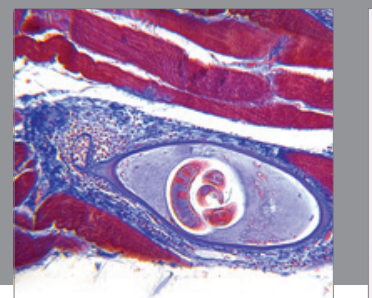

Gastroenterology

Research and Practice
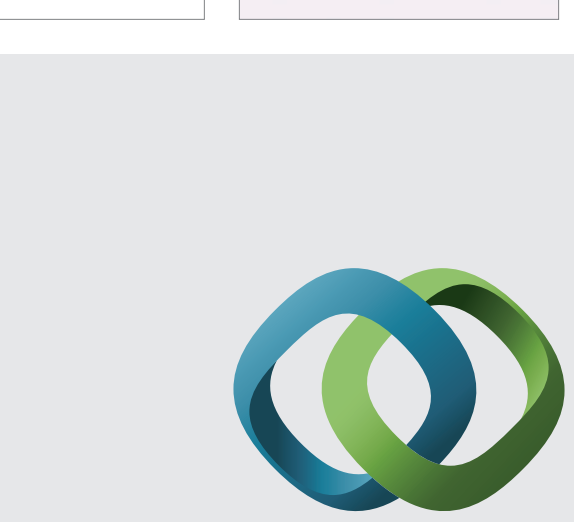

\section{Hindawi}

Submit your manuscripts at

http://www.hindawi.com
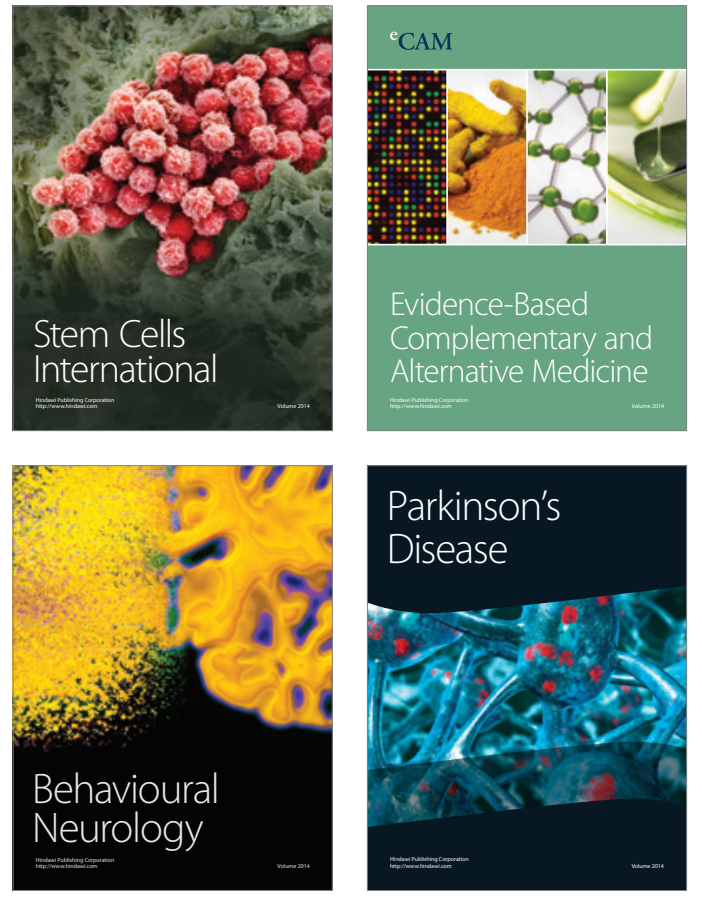
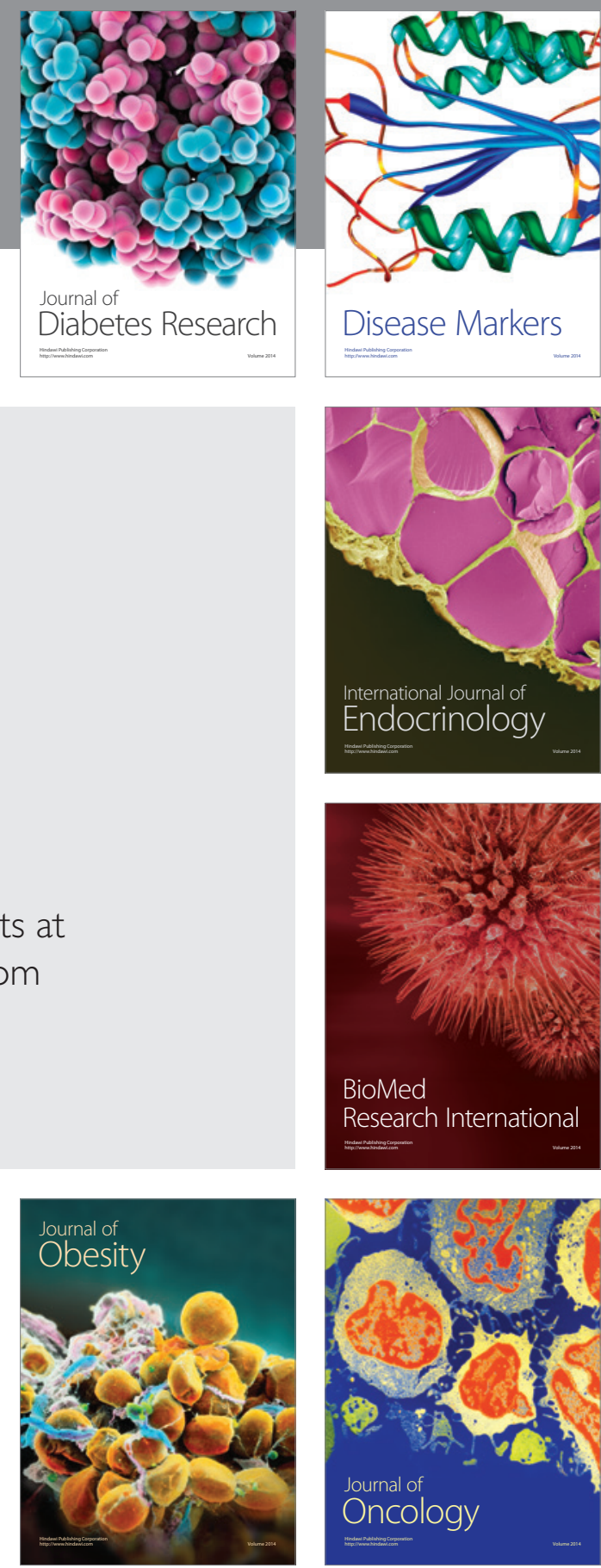

Disease Markers
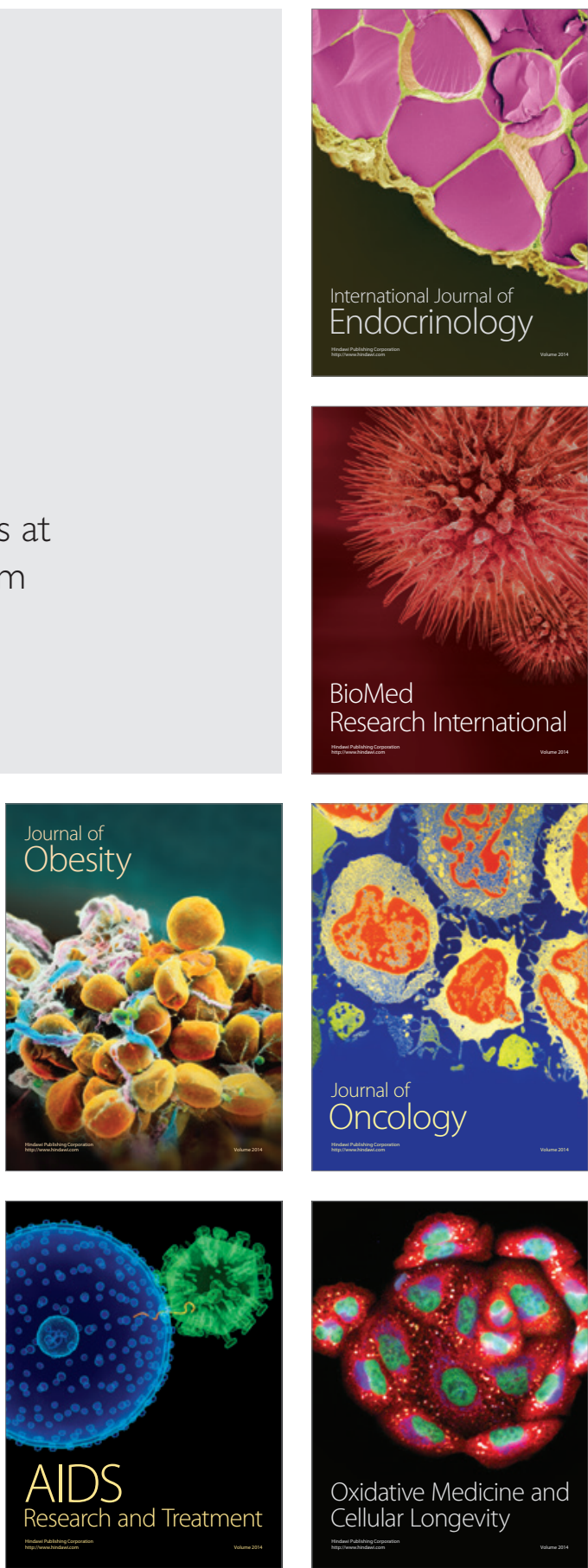